\title{
Rule Learning in Healthcare and Health Services Research
}

\author{
Rukmina Gonibala, Hadiyat Miko, Hans Lesmana, Lucia Yauri, Ellis Mirawati
}

\begin{abstract}
: in the field of healthcare successful application of machine learning need efficiency, accuracy, ability to deal with background knowledge, acceptability, transparency, exportability and ability to deal with complex data. The learning that completes the above criteria is known as rule learning. Clinical record is the most basic sort of wellbeing research. For testing the security and viability the patients volunteer take an interest in new therapeutic advancement. Presently wellbeing search depends on data. The exploration depends on organic examples and information investigation. This information is put away for treatment, charging purposes or symptomatic, and that can be the piece of other research. The second utilization of information is essential research approach in fields like general wellbeing research, wellbeing administrations examine, the study of disease transmission, examination of examples of events, assessment of medicinal services, sedate security reconnaissance, determinants, normal history of illness, and some social and hereditary investigation. The paper takes a review of rule learning in healthcare, importance of healthcare system, and also discuss about health service research.
\end{abstract}

Keywords : Rule learning, Health services research, machine learning, Healthcare system.

\section{INTRODUCTION}

The biomedical data are playing a major role in medical industry so healthcare in coming to a new era of development. The healthcare services provide benefits that it give the administrations to treatment, determination, and anticipation structure sicknesses and constrained by the great supervisory crew [1-4].

For research in healthcare field the large availability of biomedical data provide tremendous challenges and opportunities. To develop a safe and reliable tool that is based on machine learning and data-driven approaches the basic problem is to explore the associations among all the various parts of information. To create joint knowledge bases previous work use to try to connect multiple data sources. These multiple data sources can use for discovery and predictive analysis [5-7].

Revised Manuscript Received on July 22, 2019.

* Correspondence Author

Rukmina Gonibala, Institute Agama Islam Negeri (IAIN) Manado, Indonesia. E-mail: rukminagonibala@iainmanado.ac.id

Hadiyat Miko, Poltekkes Kemenkes Tasikmalaya, Indonesia.

Hans Lesmana, Poltekkes Kemenkes Makassar, Indonesia.

Lucia Yauri, Poltekkes Kemenkes Makassar, Indonesia.

Ellis Mirawati, Poltekkes Kemenkes Makassar, Indonesia.

\section{Optimization of the Research Process}

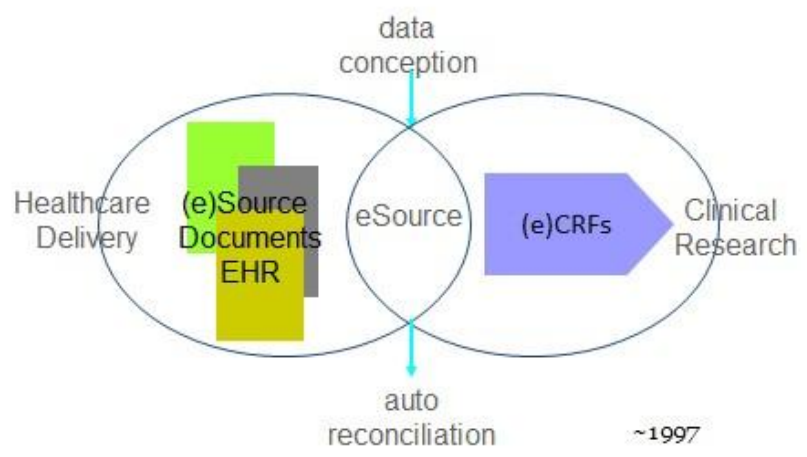

Figure1. Factors of Healthcare Research Process

Clinical record is the most fundamental type of health research. For testing the safety and efficacy the patients volunteer participate in new medical development. Now health search is based on information. The research is based on biological samples and data analysis. This data is stored for treatment, billing purposes or diagnostic, and that can be the part of other research [8]. In 2009 Lowrance [9] and 2007 Lowrance and Collins defined that the second use of data is basic research approach in fields like public health research, health services research, epidemiology, analysis of patterns of occurrences, evaluation of health care, drug safety surveillance, determinants, natural history of disease, and some social and genetic study.

\section{LITERATURE REVIEW}

Particularly with regards to a developing country the resulting usage of healthcare services and the decision of human services specialist organization it is a difficult multifaceted process. In India a sample of information feature is portrayed by low paces of usage of exceptionally sponsored open medicinal services administrations and more noteworthy use of higher evaluated private social insurance administrations. The paper [11] shows that as a level of private consumption on health in India is high as $94 \%$.

In 2012 the WHO report defined that the high expenditure on heath is large because the government expenditure is a bare of minimum 3\%. In 2007 duggal [12] described that Due to non-treatment of ailing condition; Predominance of private human services administrations is a reason for worry for the administration organizations as absence of financing choices drives 
numerous residents towards sick wellbeing or contemptible neediness. In this way in a welfare state the health care services core is relevant with the decision of human services specialist co-ops especially among open and non-open suppliers [13].

\section{HEALTH SERVICES RESEARCH (HSR)}

A multidisciplinary field for research in science is consider as Health services research (HSR) which provide the study of organisational processes, organisational structures, health technologies, affect access to health care, financial systems, quality of health, cost of health care, social factors and many more.

The Health services research provide scientific evidence to inform practices and policies and it help decision makers to face the challenges. The Health services research definition shows that its strength is depends on broad array of factors that address to understand and measure the healthcare and also depend on wide range of disciplines. Epidemiology, social sciences and medicine are included in disciplines like policy analysis, sociology and economics. As compare with the research of basic science the Health services research focus on health services, public health research and clinical research.

There are three contrasting which have interconnected perspectives are as follows:

1. Micro- at care provision level provide health technology assessment

2. Meso- at organizational level provide organisation research and service delivery

3. Macro- at system level provide health care policy analysis [14].

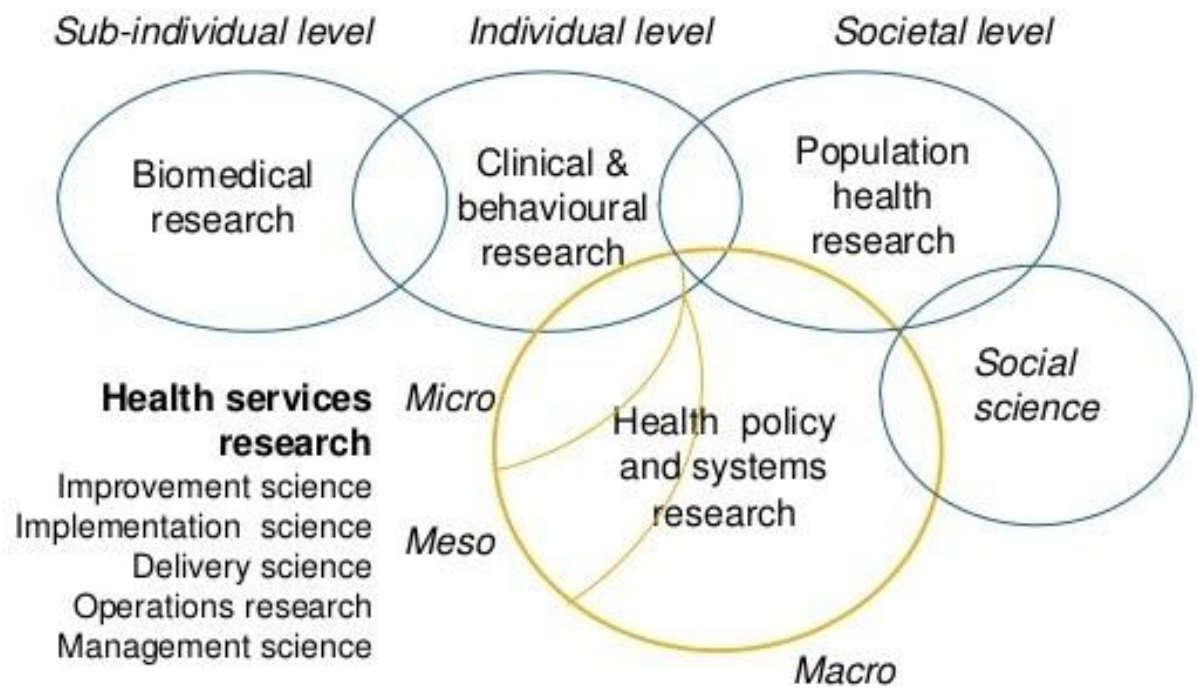

Figure 2: Focus of Health services research

\subsection{Health Policy and Health Services Research}

Health policy and Health Services Research can be defined as:

1. This can defined as a research field with multidisciplinary, rather than based on specific set of methods or disciplinary they are differentiate with problems and questions addressed through the research.

2. They are providing health service research and also include health promotion.

3. They concern about national and sub national issues including international and global issues, like the organizations that have important influences in health system and global forces

4. They explore the work of influence policy; this is the research for policy.

5. They keep the knowledge about the development of the policy and the connection of that policy to other policies [15].

\subsection{Health Services Research Method}

For advancing the knowledge and understanding the aspect of the health services system the application of scientific method is defined. For further development of disciplinary knowledge this research is contributed.

Some example of health service research methods are:

1. To measure the quality of home care developed a method

2. From hospital claims data Inferring quality of hospital care

3. Global health measure development

4. For Medicare physician develop a revising payment structure

5. Patient satisfaction measure development [16].

3.3 Process of Health services Research

For effective research the health service research process consist of many steps and actions [17][18][19]. The common steps are shown in figure 2. 


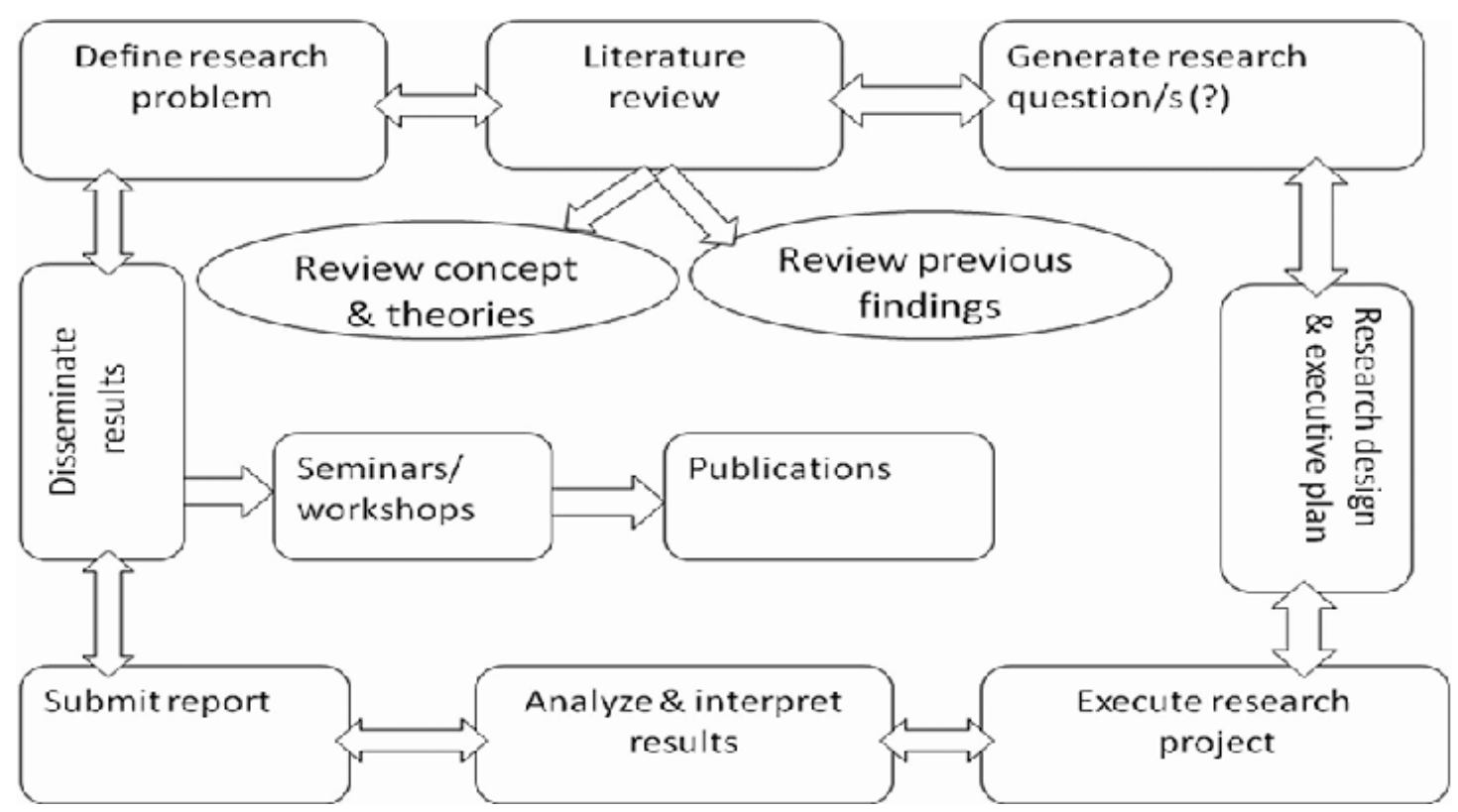

Figure 3 : Health service research process

\subsection{Goals of Health Services}

The main goal of health service is to improve and secure the health of people. In [20] defined a new health system for 21st century, the National Academy of Sciences introduced that health services goals should consist of 6 factors:

1. Safety of patients- patients should be secure during complete treatment and it should not harm by medical errors and health care services.

2. Centered patient - for every patient the healthcare services should provide personalized. In these services the person on whom the patient relies should be included. This care should provide emotional support and physical comfort.

3. Timeliness - the healthcare is organized in the manner that it provides need of patient on time.

4. Equity- the developed healthcare system should available equally for everyone.

5. Efficiency- the inefficient and waste services should eliminated in order to get a efficient health acre service.

3.5Further progress of Health Services

There are some issues which many concern are as follows:

1. in administrative databases the use of present-on admission codes

2. in administrative databases the recording of secondary diagnoses

3. coding further standardization

4. to help connect separate databases The use of Unique Patient Identifiers

5. for the experiences of patients and citizens the use of standard measurements [21].

\section{REDESIGN AND IMPROVE HEALTH CARE RULES}

Health care organizations, patients, public and private purchasers, and clinicians should work combine to design a health care processes, with the rules given below:

1. On the basis of patient value and need customization- the system should design in the manner so it can fulfill all the needs of user and it have can respond to particular patient preference and choice.
2. on continuous healing relationships based on care whenever a patient need care then it should receive in many types. Like not only face to face visit but also using smart health services. And patient should get health care at any time.

3. Reduction of waste- the healthcare system should not waste patient time and resources

4. Decision making that based on evidence- on the best available scientific knowledge Patients should receive care.

5. Free flow of information and Shared knowledge-patient should have knowledge about clinical data and its medical information.

6. Safety- the injury caused by the care system should not harm to patients. Ensure security and reduce risk is the basic requirement of any health based system

7. Clinic cooperation - to exchange of information of patients the clinic should communicate and cooperate to each other

8. Needs anticipation- rather than simply reacting to events the health system should anticipate the need of patient [22].

\section{IMPORTANCE OF HEALTH CARE}

Some important features of health care are as follows:

1. The patient who need motivational support, it provide to them

2. By using short or more frequent consultations it can boost the quality and productivity of care

3. It rapidly detect anomalies and access records of all patients

4. By using an automated system analyze the data

5. By using healthcare database tools contribute to biomedical research

6. In a structured way it interact easily and quickly by using shared tools between nurses and primary care provider [23]. 


\section{THE IMPORTANCE OF HEALTH RESEARCH}

In the society health research has high value like security. It can give significant data about results of treatment, hazard factors, illness patterns, general wellbeing intercessions, examples of consideration and useful capacities. in the field of medicinal services effective use of AI need productivity, exactness, capacity to manage foundation learning, agreeableness, straightforwardness, exportability and capacity to manage complex information. The discovering that finishes the above criteria is known as principle learning. Clinical record is the most essential kind of prosperity inquire about. For testing the security and practicality the patients volunteer look into new helpful progression. By and by prosperity search relies upon information. The investigation relies upon natural models and data examination. This data is taken care of for treatment, charging purposes or symptomatic, and that can be the bit of other research [8]. In 2009 Lowrance [9] and 2007 Lowrance and Collins portrayed that the second use of data is basic research approach in fields like general prosperity look into, prosperity organizations analyze, the investigation of infection transmission, assessment of instances of occasions, evaluation of restorative administrations, steady security observation, determinants, typical history of sickness, and some social and innate investigationThe paper takes an audit of principle learning in human services, significance of medicinal services framework, and furthermore talk about wellbeing administration examine [1].By controlling the variables that affect the result of the investigation, clinical preliminaries can give significant data about the unfavorable impacts of therapeutic intercessions and significant data about the adequacy. For improving and comparing the use of drugs, diagnostic, medical devices and vaccines input from certifiable clinical experience is additionally urgent. On the basis of clinical trial the Food and Drug Administration (FDA) approved the drug, regularly with a couple of hundred to a couple of thousand patients, but after approval of that drug it can use in many different context and on large number of people [24].

\section{INTERVENTIONS TO IMPROVE QUALITY OF HEALTH CARE}

To improve the quality of the healthcare system the managers, policy-makers, health system stakeholders, providers consider seven types of interventions categories as follows:

1. Regulation and legislation

2. Standards setting

3. for health care managers, policy-makers and workers education and information

4. Quality improvement methods and programmes should continuously used

5. Empowering and engaging communities, families and patients

6. at the front line changing clinical practice

7. Performance-based incentives establishment [25-27 ].

\section{CONCLUSION}

in the field of healthcare successful application use of machine learning need proficiency, precision, capacity to manage foundation learning, adequacy, straightforwardness, exportability and capacity to manage complex information. The discovering that finishes the above criteria is known as rule learning. The paper takes an audit of guideline learning in social insurance, significance of medicinal services framework, and furthermore talk about healthcare system, research. For examine in human services field the enormous accessibility of biomedical information give huge difficulties and openings. To build up a protected and dependable apparatus that depends on machine learning and information driven methodologies the fundamental issue is to investigate the relationship among all the different pieces of data. To make joint learning bases past work use to attempt to interface numerous information sources. These different information sources can use for disclosure and prescient examination.

\section{ACKNOWLEDGMENT}

This article has been written with financial support of RUSA-Phase 2.0 grant sanctioned vide Letter No. F. 24-51/2014-U, Policy (TNMulti-Gen), Dept. of Edn. Govt. of India, Dt. 09.10.2018.

\section{REFERENCES}

1. Janusz Wojtusiak."Rule Learning in Healthcare and Health Services Research". Machine Learning in Healthcare Informatics. pp 131-145.

2. Precision Medicine Initiative (NIH). https://www.nih.gov/pre cision-medicine-initiative-cohort-program

3. Lyman GH, Moses HL(2016). "Biomarker tests for molecularly targeted therapies - the key to unlocking precision medicine". N Engl J Med 2015,vol.375, pp.4-6.

4. Collins FS and Varmus H(2015). "A new initiative on precision medicine". N Engl J Med 2015, vol. 372, pp. 793-795.

5. Xu R, Li L and Wang Q(2014). "dRiskKB: a large-scale disease-disease risk relationship knowledge base constructed from biomedical text". BMC Bioinformatics 2015.vol.15, no.105.

6. Chen Y, Li L, Zhang G-Q, et al(2015). "Phenome-driven disease genetics prediction toward drug discovery". Bioinformatics.vol.31,pp.276-283.

7. Wang B, Mezlini AM, Demir F and et al(2015). "Similarity network fusion for aggregating data types on a genomic scale". Nat Methods 2014. vol.11, pp.333-7.

8. Baily MA, Bottrell M, Lynn J and Jennings B(2006). "The ethics of using QI methods to improve health care quality and safety". A Hastings Center Special Report. 2006,vol. 36, no.4.

9. Lowrance WW(2002). "Learning from experience, privacy and the secondary use of data in health research". London: The Nuffield Trust.

10. Lowrance WW and Collins FS(2007)."Identifiability in genomic research". Science. 2007, vol.317, pp.600-602.

11. https://www.who.int/gho/publications/world_health_statistics/EN_WHS2 012_Full.pdf

12. Ravi Duggal(2007)."Healthcare in India: Changing the Financing Strategy". Vol. 41, Issue.4, pp.386-394.

13. Chapter 2:literature https.//shodhgangainflibnet.ac.in/bit pter\%202.pdf.

14. "Health services research: helping tackle Europe's health care challenges". http://www.healthservicesresearch.eu/mediaFiles/upload/publications/Po licybrief-health-services-research.pd

15. Lucy Gilson."Health Policy and Systems Research".

16. Lynda burton. "Intoduction to Health Service Research". http://ocw.jhsph.edu/courses/HSRE/PDFs/HSRE_lect1_burton.pdf

17. Varkevisser CM, Pathmanathan I and Brownlee AT(2003). Designing and conducting health systems research projects: Proposal development and eldwork. Kit Publishers; 2003. Available from: URL http://books.google.co.in/books. 
18. Kothari CR(2004). Research methodology methods \& techniques. New Delhi: New Age International (P) Ltd.

19. Omi S(2001). "Health Research Methodology a Guide for Training in Research Methods". World Health Organization Regional Office for the Western Pacific; 2001. [cited 2012 Sep 14]. Available from: URL: http://eprints.undip.ac.id/1114/

20. Committee on Quality of Health Care in America. Crossing the quality chasm: a new health system for the 21 st century Institute of Medicine National Academy Press; Washington, DC: 2001.

21. "Policybrief-health-services-research". http://www.healthservicesresearch.eu/mediaFiles/upload/publications/Po licybrief-health-services-research.pdf

22. https://www.ncbi.nlm.nih.gov/books/NBK222277/

23. Monali Dey and Siddharth Swarup Rautaray(2014)."Study and Analysis of Data mining Algorithms for Healthcare Decision Support System ".Monali Dey et al, / (IJCSIT) International Journal of Computer Science and Information Technologies, Vol. 5, no.1. pp.470-477.

24. https://www.ncbi.nlm.nih.gov/books/NBK9571/

25. 2018"Delivering quality health services: a global imperative for universal health coverage". World Health Organization, OECD, and International Bank for Reconstruction and Development/The World Bank, 2018.

26. Elhoseny, M., Shankar, K., Lakshmanaprabu, S. K., Maseleno, A., \& Arunkumar, N. (2018). Hybrid optimization with cryptography encryption for medical image security in Internet of Things. Neural computing and applications, 1-15.

27. Tulsi Ram Bhandari(2013)."Health System Research: Development, Designs and Methods". Health System Research: Development, Designs and...JHAS.Vol. 3, No. 1 pp. 68-72. 